\title{
Late Initiation Of Breastfeeding Is A Risk Factor For Early Interruption Of Exclusive Breast Feeding A Case -control Study At Dollo Ado Refuge Camp, Somali Region, Ethiopia.
}

Dawit Getachew Gebeyehu ( $\sim$ dgetachew0482@gmail.com )

Mizan-Tepi University

Desta Haftu

Arbaminch University

Research article

Keywords: Exclusive Breastfeeding, Interruption of Exclusive Breastfeeding, Late initiation of breastfeeding, Refugee, Ethiopia, Dollo Ado

Posted Date: March 26th, 2020

DOl: https://doi.org/10.21203/rs.3.rs-19472/v1

License: (c) (1) This work is licensed under a Creative Commons Attribution 4.0 International License.

Read Full License 


\section{Abstract}

Background: Globally, nearly three fourth of infants less than-six was not exclusively-brestfeed. While in Ethiopia, the proportion was only slightly above half. In refugee, setting life is not stable, due to lack of infrastructure and adequate health care service mother and infant face many health related problems, like interruption of exclusively breastfeed which intern lead them to malnutrition and impaired growth.

Objectives: To assess the Determinants of Interruption of Exclusive Breastfeeding among mother who have infant less than six month at Dollo Ado Refugees camp, Ethiopia, 2017.

Methods: A case -control study design was conduct at Dollo Ado refugee camp from April 05 to 25, 2017. Simple random sampling technique used to select 111 eligible case and 222 controls during the study period. A structured and pretested interviewer administered questionnaire used to collect the data. Logistic regression models fitted to assess significant factor, which determine interruption of Exclusive breast-feeding in the study area.

Results: In this study not getting antenatal counseling about infant feeding ( $A-O R=5.87,2.63-13.10)$, postnatal counseling about infant feeding $(A-O R=4.33,2.7-10.78)$ and presence of problem of breastfeeding ( $A O R=10.72,4.55-25.23)$, late initiation of breastfeeding ( $A O R=4.79,2.28-10.0)$ were significant determinants of interruption of exclusive breastfeeding.

Conclusions : In this study, not getting antenatal and postnatal counseling about infant and young child feeding, problem of breastfeeding, late initiation of Exclusive breastfeeding were significant determinants of interruption of EBF. Planer and manager should focus on provision of mother advice on Infant and Young Child Feeding during Antenatal and Postnatal Care. Health professional should be alert on treating problem of breastfeeding.

\section{Introduction}

Exclusive breast-feeding is one of the elements of optimal infant and young child feeding which is defined as giving infants less than six-month only human breast milk including expressed human milk (13). World Health Organization (WHO) suggest that infant less than six month should be Exclusively breast feed as it is safe and sufficient mode of feeding to prevent infections, chronic disease and growth impairment it also helps to increase infant survival $(1,3-8)$. Globally around $70 \%$ of infants less than six month were not exclusively breastfeed In 2014 (9). In Africa, the Prevalence of interruption of exclusive breast-feeding is $68 \%$ while in Ethiopia it was nearly $50 \%$, according to Ethiopia Demographic and Health Survey (EDHS) $2011(10,11)$. Among the 10.9 million worldwide child deaths $60 \%$ of death is due to malnutrition directly or indirectly out of this $60 \%$ of deaths are during the infancy period due to inappropriate feeding (1). Only in sub Saharan Africa 1.16 million infants die in their first month of life, but if we do not miss the opportunities at home and at health facility for example EBF, we could have saved 800,000 infant deaths. In Africa the leading cause of infant mortality were $28 \%$ infection, $3 \%$ diarrhea, $25 \%$ prematurity, which are easily avertable by immunization and EBF(12). The global strategy 
of World Health Organization on infant and young child feeding (IYCF) was implementing program like Baby Friendly Hospital Initiative (BFHI) universal coding. However, the improvement was slight (13). In refugee camps, which were found in Ethiopia IYCF practices was implemented only in three of 24 camps $(14,15)$.

In Refugee, setting social service were not established due to lack of infrastructure and adequate health care service mother and infant face many health related problems, like interruption of EBF(15). Hence, care full attention should have given to IYCF especially protecting and supporting breastfeeding, which is important not just for the time of emergency only, but it have lifelong impacts on child health and on women's future preference on type of feeding $(16,17)$.

Therefore, it is very important to assess factors that may leads to the interruption of exclusive breastfeeding in accordance with the context of population type, because, it is difficult to apply the finding from community-based studies in host population. In addition, there is no specific study in Ethiopia on refugees setting. Moreover, the findings of this study will help aid organization and policy makers to set priority intervention plan for the problem, and it will help other researchers, as base line data.

\section{Determinant Factors for Interruption of Exclusive Breastfeeding}

The determinant factors for interruption of EBF has been outlined in number of literature in stable population but this factors are not well studied in emergency situation like refugee camps. In emergencies, appropriate and safe IYCF practices are less likely than under stable conditions. Bottle feeding comes with increased risks; poor water quality, an inability to sterilize the bottle/nipple, artificial ingredients in breast milk substitutes (BMS) (18). Evidences shows the a positive influence of maternal socio demographic characteristics on EBF for example as the age of the mother increase the chance of the infant being exclusively breastfeed increased $(19,20)$. Educational status affects early interruption of EBF positively (20). Mother working outside the home is inversely associated with interruption of EBF (21-26). Income was also another determine interruption of breast-feeding (27).

From obstetric factors, significant determinants of interruption of EBF includes utilization of antenatal care (ANC) and postnatal care (PNC) service, it is associated with reduced interruption of $\operatorname{EBF}(19,20,27$, 28). Following $A N C$ and $P N C$ service, guidance on EBF given to the mother about appropriate type of feeding was another protective factor against interruption of EBF. Mother who give birth in health institution were less likely to interrupt EBF than those who give birth at home (21). Type and place of delivery was also another factor which determine early interruption of EBF (22). Timely initiation of breast feeding is also another determinant for interruption of EBF in infant who were not initiated EBF within first one hour of delivery were at greater risk for interruption of EBF (28-30). Breast feeding problem of the mother like cracked nipple cause pain to the mother during breast-feeding which lead the mother to interrupt EBF early $(20,21)$. Lack of prior breastfeeding experience in prim mothers risks them for early interruption of EBF (21). In addition to the obstetric factors, Knowledge of the mother on IYCF practice is also another determinant of interruption of $\operatorname{EBF}(22,28)$. 
Factors related to the child that is defiantly important after the birth of the child like pre-lacteal that is giving infant anything before breast milk at any time after delivery favor interruption of EBF though how it does this is still debating $(20,22,31)$. Male sex and increasing age of infant (19) was risk factor for interruption of $\operatorname{EBF}(20,22,23,25,27)$. Infant who are feed the first breast milk were less likely to interrupt $\operatorname{EBF}(21,32,33)$. Mothers limited Night time breast feeding was also associated with increased risk with interruption of EBF (21).

Exclusive breast-feeding is one of the elements of optimal infant and young child feeding which is defined as giving infants less than six-month only human breast milk including expressed human milk (13). World Health Organization (WHO) suggest that infant less than six month should be Exclusively breast feed as it is safe and sufficient mode of feeding to prevent infections, chronic disease and growth impairment it also helps to increase infant survival $(1,3-8)$. Globally around $70 \%$ of infants less than six month were not exclusively breastfeed In 2014 (9). In Africa, the Prevalence of interruption of exclusive breast-feeding is $68 \%$ while in Ethiopia it was nearly $50 \%$, according to Ethiopia Demographic and Health Survey (EDHS) $2011(10,11)$. Among the 10.9 million worldwide child deaths $60 \%$ of death is due to malnutrition directly or indirectly out of this $60 \%$ of deaths are during the infancy period due to inappropriate feeding (1). Only in sub Saharan Africa 1.16 million infants die in their first month of life, but if we do not miss the opportunities at home and at health facility for example EBF, we could have saved 800,000 infant deaths. In Africa the leading cause of infant mortality were $28 \%$ infection, $3 \%$ diarrhea, $25 \%$ prematurity, which are easily avertable by immunization and EBF(12). The global strategy of World Health Organization on infant and young child feeding (IYCF) was implementing program like Baby Friendly Hospital Initiative (BFHI) universal coding. However, the improvement was slight (13). In refugee camps, which were found in Ethiopia IYCF practices was implemented only in three of 24 camps $(14,15)$.

In Refugee, setting social service were not established due to lack of infrastructure and adequate health care service mother and infant face many health related problems, like interruption of EBF(15). Hence, care full attention should have given to IYCF especially protecting and supporting breastfeeding, which is important not just for the time of emergency only, but it have lifelong impacts on child health and on women's future preference on type of feeding $(16,17)$.

Therefore, it is very important to assess factors that may leads to the interruption of exclusive breastfeeding in accordance with the context of population type, because, it is difficult to apply the finding from community-based studies in host population. In addition, there is no specific study in Ethiopia on refugees setting. Moreover, the findings of this study will help aid organization and policy makers to set priority intervention plan for the problem, and it will help other researchers, as base line data.

\section{Determinant Factors for Interruption of Exclusive Breastfeeding}

The determinant factors for interruption of EBF has been outlined in number of literature in stable population but this factors are not well studied in emergency situation like refugee camps. In 
emergencies, appropriate and safe IYCF practices are less likely than under stable conditions. Bottle feeding comes with increased risks; poor water quality, an inability to sterilize the bottle/nipple, artificial ingredients in breast milk substitutes (BMS) (18). Evidences shows the a positive influence of maternal socio demographic characteristics on EBF for example as the age of the mother increase the chance of the infant being exclusively breastfeed increased $(19,20)$. Educational status affects early interruption of EBF positively (20). Mother working outside the home is inversely associated with interruption of EBF (21-26). Income was also another determine interruption of breast-feeding (27).

From obstetric factors, significant determinants of interruption of EBF includes utilization of antenatal care (ANC) and postnatal care (PNC) service, it is associated with reduced interruption of $\operatorname{EBF}(19,20,27$, 28). Following ANC and PNC service, guidance on EBF given to the mother about appropriate type of feeding was another protective factor against interruption of EBF. Mother who give birth in health institution were less likely to interrupt EBF than those who give birth at home (21). Type and place of delivery was also another factor which determine early interruption of EBF (22). Timely initiation of breast feeding is also another determinant for interruption of EBF in infant who were not initiated EBF within first one hour of delivery were at greater risk for interruption of EBF (28-30). Breast feeding problem of the mother like cracked nipple cause pain to the mother during breast-feeding which lead the mother to interrupt EBF early $(20,21)$. Lack of prior breastfeeding experience in prim mothers risks them for early interruption of EBF (21). In addition to the obstetric factors, Knowledge of the mother on IYCF practice is also another determinant of interruption of $\operatorname{EBF}(22,28)$.

Factors related to the child that is defiantly important after the birth of the child like pre-lacteal that is giving infant anything before breast milk at any time after delivery favor interruption of EBF though how it does this is still debating $(20,22,31)$. Male sex and increasing age of infant (19) was risk factor for interruption of $\operatorname{EBF}(20,22,23,25,27)$. Infant who are feed the first breast milk were less likely to interrupt $\operatorname{EBF}(21,32,33)$. Mothers limited Night time breast feeding was also associated with increased risk with interruption of EBF (21).

\section{Methods}

\section{Study design and setting}

A case -control study design was conduct at Dollo Ado refugee camp from April 05 to 25, 2017. Dollo Ado Refugee Camp found in Ethiopia Somali Region Liben Zone Dollo Ado Woreda, $935 \mathrm{~km}$ away from Addis Ababa in the southeast direction with around 111,000 host population. Dollo Ado Refugee Camp is one of the 24-Refugee Camps in the country. A total of 251,987 Somalia refugees' population hosted in the five camps Bokolmayo, Melkadida, Kobe, heliwoyn and Bura amino. The Ethiopian Government provides protection for refugees in collaboration with national, international NGO's, and UN agencies $(10,11,14$, 15).

\section{Study population and sampling}


All mothers who have infant less than six month at Dollo Ado Refugee Camp, who comes for collection of ration during the study period were given screening question using a 24 hour recall to classify their breast-feeding status. Mothers, who were severely ill and unable to respond excluded from the study. OpenEpi Version 3 statistical software for unmatched case control studies used to calculate the sample size considering the following assumption: two sided confidence level of $95 \%$, Power of $80 \%$, and Ratio of case to control one to two. By taking the proportion of exposure among cases from previous study using significant factors with Adjusted OR( A- OR) the maximum sample size was taken which is 302 , adding $10 \%$ for non-response rate the final sample size were 333 , (111 cases and 222 controls ). The sampling technique followed identification and coding of mothers whose index infant was less than six month from ration registration in Dollo Ado Refugee Camps. On the day of ration distribution, the breastfeeding status of infant less than six month were asked using a 24-hour recall method which is recommended by WHO, to identify case and control. Mother who have infant less than six month and responded yes for the screening question that is "have you given anything to eat or drink to your infant in the previous 24 hour or in the previous day and night" considered as case and who answered no considered as controls. After identifying eligible case and control, by using computer generated random number case and control where recruited with one to two propositi-ratio in the aforementioned refugee camp.

\section{Data collection and analysis}

Mothers identified as case and control interviewed using structured and pretested questionnaire adapted from EDHS 2016. The questionnaire was prepared in English language, translated to Somali language, and retranslated to original language to check for consistency. The questionnaire used to collect information on maternal socio demographic factors and maternal service use, which determine interruption of EBF from study population. Ten trained data collectors two to each camp and five Bsc nurse supervisor one to each camp recruited. Descriptive and summary statistic carried out to describe study participants according to different characteristics. In binary logistic regressions model first a bivariate logistic regression performed for each independent variable with the outcome variable interruption of EBF to identify factors associated with interruption EBF practice at $\leq 0.2$. Finally, multiple logistic regression model implemented to determine independent predictors of interruption of EBF.

Adjusted odds ratios (AOR) with $95 \%$ confidence interval $(\mathrm{Cl})$ and $p$ values of less than 0.05 considered statistically significant association in the final model.

\section{Terms and operational definitions}

Case: Those mothers, who have infant less than six month, received any other feeding (animal milk, formula feeds, soups, water etc) besides mother's breast milk in the previous 24-hour hour.

Controls: Those mother who have infant less than six month whose infant were Exclusively Breastfed in the previous 24-hour. 
Knowledge of mother is Mother's information on the advantages and recommended duration of exclusive breastfeeding.

Timely initiation of breastfeeding: infants who putted to the breast within one hour of birth

Prelacteal feeding: children who have given something other than breast milk during the first three days of life before they putted to the breast.

\section{Results}

\section{Socio-Demographic characteristics of study participant}

All study participants were Muslim by religion and speaks Somali language. The mean ( \pm SD) age of mothers was $25( \pm 5)$. Rahan-wayn is the largest ethnic group, followed by Merihan and Hawiye. Majority of the mother were married, uneducated and all most all of the mother work inside home (Table 1).

Table 1 Socio-demographic characteristics of study participant, Dollo Ado Refugee Camp, 2017.

\begin{tabular}{|c|c|c|c|}
\hline Exposure variables & $\begin{array}{l}\text { Cases n (\%) } \\
\mathrm{N}=111\end{array}$ & $\begin{array}{l}\text { Controls n (\%) } \\
\mathrm{N}=222\end{array}$ & C- OR $(95 \% \mathrm{CI})$ \\
\hline \multicolumn{4}{|l|}{ Ethnicity } \\
\hline Rahan-wayn & $59(57)$ & $118(56)$ & \\
\hline Hawiye & $25(24)$ & 36 (17) & \\
\hline Marehan & $18(17)$ & $44(21)$ & \\
\hline Others* & $1(1)$ & $11(5)$ & \\
\hline \multicolumn{4}{|l|}{ Marital status } \\
\hline married & $84(82)$ & 167(80) & 1 \\
\hline single & $19(18)$ & $47(20)$ & $1.11(0.61,2.03)$ \\
\hline \multicolumn{4}{|l|}{ Educational status } \\
\hline Educated & $6(7)$ & $25(22)$ & 1 \\
\hline Uneducated & $94(91)$ & $183(88)$ & $1.02(0.62,1.70)$ \\
\hline \multicolumn{4}{|l|}{ Occupational status } \\
\hline work at home & $84(82)$ & $167(80)$ & 1 \\
\hline work outside home & $9(9)$ & $26(12)$ & $1.48(.66,3.29)$ \\
\hline \multicolumn{4}{|l|}{ Parity } \\
\hline uni para & $28(27)$ & $51(24)$ & $2.3(1.02,4.03)$ \\
\hline multi para & 75 (73) & $158(73)$ & 1 \\
\hline \multicolumn{4}{|l|}{ Birth interval } \\
\hline$<$ two year & $71(69)$ & $135(65)$ & $0.82(0.49,1.36)$ \\
\hline$>$ two year & $32(31)$ & $74(35)$ & 1 \\
\hline
\end{tabular}




\section{Determinant Factors for Interruption of Exclusive Breastfeeding}

Antenatal care service utilization of the study participant almost universal, Mother who has ANC advice on breast-feeding was $57 \%$ and $92 \%$ among case and control respectively. Place of delivery is $100 \%$ institutional in all of case and control as it privileged them to have immediate birth certificate. Concerning initiation of EBF $47 \%$ of case and $86 \%$ control initiated timely. All of the interviewed mothers responded that they had feed their infants the first breast milk (colostrum) in both group, but prevalence of prelactel feeding is $96 \%$ and $87 \%$ in case and control respectively. The main food item used is water or tea, which is $83 \%$ among case and $100 \%$ among controls. PNC care service utilization of the mother in the study is $73 \%$ in case and $94 \%$ in control groups; out of this, $76 \%$ of case and $88 \%$ of control have PNC advice on IYCF. History of bottle-feeding reported in $36 \%$ of case and $46 \%$ of control. Mother who have breastfeeding problem were $35 \%$ of case and $7 \%$ of control. The main type of problem were pain in breast $50 \%$ in case group followed by inadequate breast milk with $31 \%$ in case and $86 \%$ of control, the other problem were refusal of baby $19 \%$ of case and in $14 \%$ of control. The mean ( \pm SD) age of infants were $3( \pm 1)$ months $54 \%$ case and $52 \%$ of controls are male sex.

In the binary logistic regression model Not getting ANC advice on infant and young child feeding has significant association ( $\mathrm{C}-\mathrm{OR}=8.02,4.45-14.42)$ and not getting PNC advice on IYCF (C-OR = 8.09, 4.30 - 15.23) has a significant association. In addition mother who have problem of breastfeeding (C-OR = $8.67,4.67-16.14)$, late initiation of breastfeeding ( $C-O R=7.23,4.16-12.56)$, poor knowledge status of the mother about infant and young child feeding $(\mathrm{C}-\mathrm{OR}=2.48,1.48-4.15)$ were significant determinants of interruption of EBF at $p$ value less than 0.05 .

Table 2 Result of bivariate analyses of determinants of interruption of EBF among mothers who have infant less than six month, at Dollo Ado refugee camp

\begin{tabular}{|c|c|c|c|c|c|c|}
\hline & & \multicolumn{2}{|c|}{ Case } & \multicolumn{2}{|c|}{ Control } & \multirow[t]{2}{*}{ C-OR $(95 \% \mathrm{CI})$} \\
\hline & & freq & $\%$ & freq & $\%$ & \\
\hline \multirow[t]{2}{*}{ Marital status } & Married & 84 & 82 & 167 & 80 & 1 \\
\hline & Single & 19 & 18 & 42 & 20 & $1.11(0.61,2.03)$ \\
\hline \multirow[t]{2}{*}{ Educational status } & Educated & 32 & 31 & 66 & 32 & 1 \\
\hline & Uneducated & 71 & 69 & 143 & 68 & $1.02(0.62,1.70)$ \\
\hline \multirow[t]{2}{*}{ Occupational status } & Work At Home & 94 & 91 & 183 & 88 & 1 \\
\hline & Outside Home & 9 & 9 & 26 & 12 & $1.48(.66,3.29)$ \\
\hline \multirow[t]{2}{*}{ Birth spacing } & $<$ two year & 71 & 69 & 135 & 65 & $0.82(0.49,1.36)$ \\
\hline & $>$ two year & 32 & 31 & 74 & 35 & 1 \\
\hline \multirow[t]{2}{*}{ Parity } & Uni para & 28 & 27 & 51 & 24 & $2.3(1.02,4.03)$ \\
\hline & Multi para & 75 & 73 & 158 & 73 & \\
\hline \multirow{2}{*}{$\begin{array}{l}\text { ANC advice } \\
\text { On infant feeding }\end{array}$} & No & 50 & 49 & 22 & 11 & $8.02(4.45,14.42)^{*}$ \\
\hline & Yes & 53 & 51 & 187 & 89 & 1 \\
\hline \multirow[t]{2}{*}{ PNC visit } & No & 27 & 26 & 12 & 6 & $5.71(2.75,11.85)^{*}$ \\
\hline & Yes & 76 & 74 & 193 & 94 & 1 \\
\hline PNC advice on infant feeding & No & 43 & 42 & 17 & 8 & $7.9(4.30,15.23)^{*}$ \\
\hline
\end{tabular}




\begin{tabular}{|c|c|c|c|c|c|c|}
\hline & Yes & 60 & 58 & 192 & 92 & 1 \\
\hline \multirow[t]{2}{*}{ Problem of breastfeeding } & Yes & 46 & 45 & 18 & 9 & $8.67(4.67,16.14)^{*}$ \\
\hline & No & 56 & 55 & 190 & 91 & 1 \\
\hline \multirow[t]{2}{*}{ Initiation of breastfeeding } & Timely initiation & 47 & 46 & 176 & 86 & 1 \\
\hline & Late initiation & 56 & 54 & 29 & 14 & $7.23(4.16,12.56)^{*}$ \\
\hline \multirow[t]{2}{*}{ Gender of the baby } & Male & 56 & 54 & 105 & 50 & $1.18(0.74,2.00)$ \\
\hline & Female & 47 & 46 & 104 & 50 & 1 \\
\hline \multirow[t]{2}{*}{ Baby health } & Yes & 25 & 26 & 42 & 23 & $1.16(0.66,2.06)$ \\
\hline & No & 73 & 74 & 143 & 77 & 1 \\
\hline \multirow[t]{2}{*}{ Knowledge mother on EBF } & Poor knowledge & 41 & 40 & 44 & 21 & $2.48(1.48,4.15)^{*}$ \\
\hline & Good knowledge & 62 & 60 & 165 & 79 & \\
\hline
\end{tabular}

- OR: Crude Odds Ratio

$* \mathrm{P}<0.2$

able 3 was omitted by the authors in this version of the paper.

able 4, Result of multivariate analyses of determinants of interruption of EBF

\begin{tabular}{|c|c|c|c|c|}
\hline \multirow[t]{2}{*}{ Variables } & Cases n (\%) & Controls n (\%) & C-OR $(95 \%$ CI) & \multirow[t]{2}{*}{ A-OR $(95 \% \mathrm{CI})$} \\
\hline & $\mathrm{N}=111$ & $\mathrm{~N}=222$ & & \\
\hline \multicolumn{5}{|c|}{ ANC advice on IYCF } \\
\hline Yes & $57(56)$ & $180(92)$ & 1 & 1 \\
\hline No & $45(44)$ & $16(8)$ & $8.02(4.45,14.42)^{*}$ & $5.87(2.63,13.10)^{* *}$ \\
\hline \multicolumn{5}{|l|}{ Postnatal visit } \\
\hline Yes & $76(74)$ & $192(94)$ & 1 & 1 \\
\hline No & $27(26)$ & $12(6)$ & $5.71(2.75,11.85)^{*}$ & $3.41(1.09,10.60)$ \\
\hline \multicolumn{5}{|c|}{ PNC advice on IYCF } \\
\hline Yes & $59(76)$ & $171(88)$ & 1 & 1 \\
\hline No & $19(24)$ & $24(12)$ & $8.09(4.30,15.23)^{*}$ & $4.33(2.7,10.78) * *$ \\
\hline \multicolumn{5}{|c|}{ Problem of breastfeeding } \\
\hline Yes & $32(33)$ & $14(7)$ & $8.67(4.67,16.14)^{*}$ & $10.72(4.55,25.23) * *$ \\
\hline No & $66(67)$ & $192(93)$ & 1 & \\
\hline \multicolumn{5}{|c|}{ Knowledge status of mother on EBF } \\
\hline Good Knowledge & $62(60)$ & 165 (79) & 1 & 1 \\
\hline Poor Knowledge & $41(40)$ & $44(21)$ & $2.48(1.48,4.15)^{*}$ & $1.61(0.77,3.35)$ \\
\hline \multicolumn{5}{|c|}{ Initiation of Exclusive breast feeding } \\
\hline Timely initiation & $47(46)$ & $176(86)$ & 1 & 1 \\
\hline Late initiation & $56(54)$ & $29(14)$ & $7.23(4.16,12.56)^{*}$ & $4.79(2.28,10.0) * *$ \\
\hline
\end{tabular}

C- OR: Crude Odds Ratio

A- OR: Adjusted Odds Ratio

$* \mathrm{P}<0.2$

$* * \mathrm{P}<0.05$ 


\section{Discussion}

This study shows that not getting antenatal and postnatal counseling on infant feeding, problem of breastfeeding, timely initiation of breastfeeding where found to be determinants of interruption of Exclusive breastfeeding. While marital status, educational, status occupational status, birth spacing, parity, ANC visit gender, age, health of the baby, knowledge mother on EBF were not associated with interruption of EBF.

Not getting Antenatal counseling on Exclusive breastfeeding was a risk factor for interruption of exclusive breastfeeding. In this study, mother who did not receive antenatal counseling on Infant and Young Child Feeding practice while she was pregnant were 5.87 times more likely her infant to interrupt exclusive breastfeeding than mother who have ANC counseling about infant feeding. This could be explained to the fact that mother who have got IYCF counseling on EBF will have time to prepare her selves on appropriate type of infant feeding $(19,20,27,28)$. This is may be the result of motivation by health professionals especially midwives who teach mothers about appropriate infant and young child feeding practices during ANC visit.

In this study mother who did not receive postnatal counseling on infant feeding while she was pregnant was 4 times more likely her infant to interrupt exclusive breastfeeding than those mother who have PNC counseling on infant feeding. This is in line with other studies done in Ethiopia $(19,23)$.

Problem of breastfeeding put infant on greater risk for interruption of EBF, mother who have experienced breastfeeding problem were 10 times more likely her infant to interrupt exclusive breastfeeding compared to mothers who do not have breastfeeding problem on the previous 24-hour recall. This finding is in line with other study result multi center studies in eight different countries (20). This is may be due to inflammation of the breast, cracked nipple that cause pain to the mother or even lack of self-confidence on breast milk or the baby refuses to suck due to mouth ulcer.

Late initiation of breastfeeding was also a major determinant factor for interruption of exclusive breastfeeding. In this study mothers who had initiated breast-feeding lately or one hour after delivery of index infant were 7.7 times more likely to interrupt EBF when compared with those mother who had initiated breast-feeding immediately after birth or within the first one hour of the birth of the index infant to their infant. This is may be infant may adapt what they have given immediately after birth and it increase their bondage with mother, this may affect infant feeding preference in other way mother who give breast immediately to their infant will continue feeding exclusively only their breast milk because they think that the infant cant adapt other food items. This is also consistent with several studies done in Ethiopia (28-30).

\section{Strength And Limitation}


This study tried to address interruption of EBF on most vulnerable population at most peripheries this may be one of the strength and it also used 24- recall method, which minimizes mothers recall bias. However, not addressing the qualitative aspect of the problem was its limitation. In addition, the study result was compared with the results from stable population due to shortage of literature in refugee population.

\section{Conclusion}

The finding of this study has shown that not getting antenatal and postnatal counseling about infant feeding, problem of breastfeeding timely initiation of breastfeeding was significant determinants of interruption of Exclusive breastfeeding.

The recommendation to halt the interruption of exclusive breastfeeding in the study areas are focusing on antenatal and postnatal counseling on infant and young child feeding. Health professional and community health worker should be alert on advising mother how to feed their infant especially timely initiation and to treat problem of breast-feeding, like breast pain, refusing baby due to oral trash, teach mothers to have self-confidence in case of inadequate breast milk. Managers and policy makers should have to prioritize there action plan not only on the increment proportion of EBF but also on reducing factors which risks interruption of EBF in the study area. Researchers recommended conducting similar study in the area with another design like longitudinal and tray to explore barriers of exclusive breastfeeding qualitatively.

\section{Abbreviations}

ANC: antenatal care; BF: breastfeeding; EBF: exclusive breastfeeding; EDHS: Ethiopian demographic and health survey; HIV: Human immunodeficiency virus; IYCF: Infant and young child feeding; NGO: Non Governmental organization; ORS: Oral rehydration salt; SDG: Sustainable development goals; UNICEF: United Nations children's fund; USAID: United State agency for international development; WHO: World health organization

\section{Declarations}

\section{Acknowledgements}

First, we want to thank Ethiopian National Intelligence and Security Service - Administration of Refugee and Returnee Affair (ENISS-ARRA) head office at Addis Ababa they allow us to conduct this research by writing letter of support to Dollo Ado Refugee Camp. Then our gratitude goes to Dolo Ado Refugee Program Coordination Office especial thank to Mr. Daniel, Mr. Adhanom Mr. Tekleweni and Mr. Mahadi for their support mainly by providing necessary data, material and transport to conduct the research. In addition, we want to thank the Federal Police South Division, friends and many others individual and organization for whatever support we have received while we were conducting this study. 


\section{Funding}

Not applicable

\section{Availability of data and materials}

The datasets used are available

\section{Authors' contributions}

DGG initiate the concept wrote the proposal, participated in data collection, analyzed the data and drafted the paper. DH approved the proposal with some revisions, participated in data analysis and revised subsequent drafts of the paper and commented the final paper and manuscript. All authors read and approved the final manuscript.

\section{Competing interests}

The authors declare that they have no any competing interests.

\section{Consent for publication}

Not applicable

\section{Ethics approval and consent to participate}

The study conducted after obtaining approval from Arbaminch University (AMU) Research Ethics Review Committee (RERC) and letter of support from AMU department of public health and Post Graduate (PG). A letter of permission also secured from Ethiopian National Intelligence and Security Service Administration for Refugee and Returnee Affair (ENISS-ARRA) head office at Addis Ababa and Dolo Ado Refugee Program Coordination Office at Melkadida sub office. All study participants provided written consent, they have signed in their fingerprint, and they had told the benefit, harm and the right to refuse to participate or even to discontinue the interview at any moment when they need or feel discomfort or to question anything concerning the study.

\section{Author details}

${ }^{1}$ Department of Public Health, College of Medicine and Health Science, Mizan-Tepi University, Mizan Teferi, Ethiopia.

${ }^{2}$ Department of Public Health, College of Medicine and Health Science, Arbaminch University, Arbaminch, Ethiopia.

\section{References}

Uncategorized References 
1. WHO, UNICEF. The Global Strategy for Infant and Young Child Feeding. Geneva: World Health Organization,; 2003.

2. WHO, UNICE. A joint WHO/UNICEF statement Protecting, promoting and supporting breastfeeding: the special role of maternity services. In: World Health Organization, editor. Geneva, 1989.

3. WHO, UNICEF. Indicators for assessing infant and young child feeding practices. In: development Docha, organization wh, editors. . Geneva: WHO press,; 1991.

4. WHO/UNICEF. Global nutrition targets 2025 breastfeeding policy brief. Geneva: World Health Organization; 2014.

5. Engebretsen IM, Jackson D, Fadnes LT, Nankabirwa V, Diallo AH, Doherty T, et al. Growth effects of exclusive breastfeeding promotion by peer counsellors in sub-Saharan Africa: the cluster-randomised PROMISE EBF trial. BMC public health. 2014;14:633.

6. Report On The Situation Of Infant And Young Child Feeding In Ethiopia In: Network IBFA, editor. The committee on the rights of the child. Geneva: Infant Feeding Association (IBFAN - GIFA) - IBFAN global liaison office; 2015

7. Owais A, Schwartz B, Kleinbaum DG, Suchdev PS, Faruque AS, Das SK, et al. Minimum Acceptable Diet at 9 Months but Not Exclusive Breastfeeding at 3 Months or Timely Complementary Feeding Initiation Is Predictive of Infant Growth in Rural Bangladesh. PloS one. 2016;11(10):e0165128.

8. Kramer MS, Kakuma R. Optimal duration of exclusive breastfeeding. The Cochrane database of systematic reviews. 2012(8):CD003517.

9. International Food Policy Research Institute: Global Nutrition Report 2016: From Promise to Impact: Ending Malnutrition by 2030. Washington, DC2016.

10. Central Statistical Agency [Ethiopia] and ICF International.Ethiopia and Calverton M, USA: Central Statistical Agency and ICF International. . Ethiopia Demographic and Health Survey 2011. Addis Ababa2012.

11. Macro CSAEaO. Ethiopia demographic and health survey 2016 preliminary. Ethiopia and Calverton, Maryland, USA: Central Statistical Agency and ORC Macro 2016. Addis Ababa2016.

12. Opportunities for Africa's Newborns,Practical data, Policy and Programtic support for New born Cre in Africa [press release]. Cape Town: PMNCH2006.

13. Brownell EA, Hagadorn JI, Lussier MM, Goh G, Thevenet-Morrison KN, Lerer TJ, et al. Optimal periods of exclusive breastfeeding associated with any breastfeeding duration through one year. The Journal of pediatrics. 2015;166(3):566-70 e1.

14. Ethiopia fact sheet : population of concern [press release]. UNHCRJune 2016.

15. Ethiopia hosts largest number of refugees in Africa. The Guardian. 2014.

16. Emergencies laYCFi. Operational Guidance for Emergency Relief Staff and Programme Managers. Version 2.1 ed: IFE Core Group; 2007.

17. A. TN, M. HV, A.V. W. Survival Analysis of Duration of Exclusive Breast Feeding Using Life Table and Hazard Function. Journal of Krishna Institute of Medical Sciences University. 2015;4(1). 
18. Frega GFaM. Responding to nutrition gaps in Jordn in the seryain refugees crisis:Infant and young child feeding eduction and malnutrtion treatment february 2014.

19. Teka B, Assefa H, Haileslassie K. Prevalence and determinant factors of exclusive breastfeeding practices among mothers in Enderta woreda, Tigray, North Ethiopia: a cross-sectional study. Int Breastfeed J. 2015;10(1):2.

20. Asemahagn MA. Determinants of exclusive breastfeeding practices among mothers in azezo district, northwest Ethiopia. Int Breastfeed J. 2016;11:22.

21. Graciete $\mathrm{O}$, Camilla dC, Tatiana dO, Nelson F, Luciana R. Factors predicting early discontinuation of exclusive breastfeeding in the first month of life. Jornal de Pediatria 2010 8(5):444.

22. Seid AM, Yesuf ME, Koye DN. Prevalence of Exclusive Breastfeeding Practices and associated factors among mothers in Bahir Dar city, Northwest Ethiopia: a community based cross-sectional study. International breastfeeding journal. 2013;8(1):14.

23. Tesfaye S. Tefera B. Mulusew G. KDADaSBU. Factors associated with exclusive breastfeeding practices among mothers in Goba district, south east Ethiopia: a cross-sectional study. International Breastfeeding Journal 2012;7(17).

24. Asfaw MM, Argaw MD, Kefene ZK. Factors associated with exclusive breastfeeding practices in Debre Berhan District, Central Ethiopia: a cross sectional community based study. Int Breastfeed J. 2015;10:23.

25. Misgan Legesse Liben Yohannes Bacha Gemechu2 MA, Adugnaw Asrade, Belete Adamie, Ehitemelak Gebremedin and Yibel Melak. Factors associated with exclusive breastfeeding practices among mothers in dubti town, afar regional state, northeast Ethiopia: a community based crosssectional study. International Breastfeeding Journal. 2016.

26. Migration and health: key issues. http://www.euro.who.int/en/publications/policy-documents; 2015.

27. Agho KE, Dibley MJ, Odiase Jl, Ogbonmwan SM. Determinants of exclusive breastfeeding in Nigeria. BMC Pregnancy Childbirth. 2011;11:2.

28. Sonko A, Worku A. Prevalence and predictors of exclusive breastfeeding for the first six months of life among women in Halaba special woreda, Southern Nations, Nationalities and Peoples' Region/SNNPR/, Ethiopia: a community based cross-sectional study. Archives of public health = Archives belges de sante publique. 2015;73:53.

29. Liben ML, Gemechu YB, Adugnew M, Asrade A, Adamie B, Gebremedin E, et al. Factors associated with exclusive breastfeeding practices among mothers in dubti town, afar regional state, northeast Ethiopia: a community based cross-sectional study. Int Breastfeed J. 2016;11:4.

30. Tadesse T, Mesfin F, Chane T. Prevalence and associated factors of non-exclusive breastfeeding of infants during the first six months in rural area of Sorro District, Southern Ethiopia: a cross-sectional study. International breastfeeding journal. 2016;11:25.

31. M. G, E. M. Exclusive breastfeeding and associated factors among mothers in Debre Markos, Northwest Ethiopia: a cross-sectional study. International Breastfeeding Journal 2015;10(1). 
32. Crystal L.Ali T. Ramya A. Cebisa N. Ram K. Anuradha B. Shamsir A. Maribel P. MLLEobotM-En. Early interruption of exclusive breastfeeding: results from the eight-country MAL-ED study. Patil et al Journal of Health, Population and Nutrition. 2015; 34(10).

33. Patil CL, Turab A, Ambikapathi R, Nesamvuni C, Chandyo RK, Bose A, et al. Early interruption of exclusive breastfeeding: results from the eight-country MAL-ED study. Journal of health, population, and nutrition. 2015;34:10. 